Indian Section.

\title{
History of the Dhanbad and District Leprosy Clinics.
}

C. S. Ryles.

7 HE Jharia Mines Board of Health having allotted Rs. 1,600 for leprosy work in the 1932-33 budget, it was resolved to open a clinic at Jharia on April 1st, 1932. Jharia was chosen because it was the largest town in the coalfield area, and there are disused sweepers' quarters there which were capable of conversion into a suitable clinic. There is room for about 10 beds, though so far there has been no attempt to keep patients in hospital.

The clinic at Jharia was largely attended from the first, so much so that the necessity for further clinics quickly became evident. Patients attend not only from the collieries, but also from villages, many of them 20 or more miles away.

From a cinema charity performance held at Jharia in March, 1932, a sum of Rs. 750 accrued which was earmarked for feeding the patients. This was good propaganda, because the Indian's idea of benevolence leans towards feeding something, whether it be the priests or the poor, or cattle or other animals; thus their interest in the leprosy work was enlisted from the beginning.

In April, 1932, a public meeting was convened to devise a suitable means of perpetuating the memory of Dr. G. C. Ghosh, a skilful and popular physician, who had recently died. There had been some idea of endowing a bed in the local hospital but, instead, the meeting was induced to form " The Dr. G. C. Ghosh Memorial Leper Fund." A large committee was appointed and a few meetings were held, but few took any interest in its activities, till finally it was absorbed into another body, to be mentioned. The clinic later opened at Katras was called "The Dr. G. C. Ghosh Memorial Leprosy Clinic."

On 2nd June, 1932, another public meeting was called at Dhanbad, with the Additional Deputy Commissioner in the chair, when The Dhanbad and District Leprosy Relief Fund was formed. Mr. S. R. Zaman, I.C.S., was appointed Chairman, Rai H. P. Banerji Bahadur, Honorary Treasurer ; Dr. C. S. Ryles, Honorary Secretary; and a strong and influential committee, representative of all classes of the community. This body shows no signs of inanition as yet.

On 1st September, 1932, a second clinic was opened near 
SAMPLE VILLAGE CARD

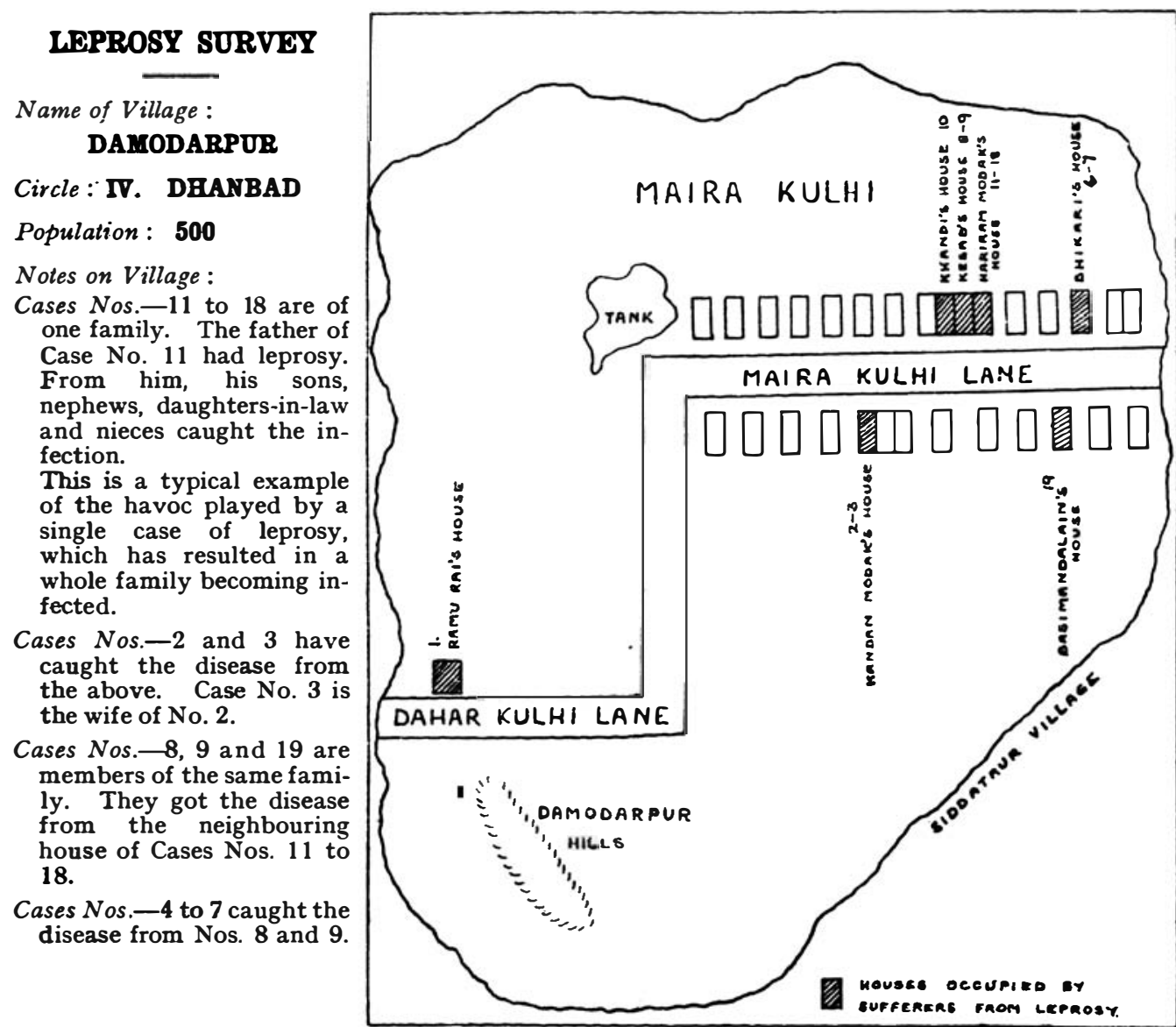

Serial Nam

1 Ramu Rai

Reg. Age Sex Caste Type

Remarks

2 Kandan Modak 27535 M Maira

$\mathrm{N}_{3}$ Cousin of No. 11

3 Nidhi $27730 \mathrm{~F}$ do

4 Bhikari Mandal 27840 M Mandal

$\mathrm{N}_{2}$ Wife of No. 2

5 Pabodi

(Suri)

6 Amodi $28012 \mathrm{~F}$ do.

7 Mohi $28165 \mathrm{~F}$

do.

$N_{1}$ Daughter of

$28238 \mathrm{MI}$

do.

$\mathrm{N}_{1}$

do.

8 Kesab Mandal'

do.

$9 \mathrm{Ilmi}$ $28312 \mathrm{~F}$

$\mathrm{N}_{1}$ Mother of No. 4

$\mathrm{C}_{1}$, Neighbour of

$\mathrm{N}_{3}$ No. 11

$\mathrm{N}_{1}$ Daughter of

$$
\text { L.C.R. No. } 57
$$

10 Khandi

$28416 \mathrm{~F}$ do.

11 Hariram Modak 28545 M Maira

12 Lerhu

$28625 \mathrm{M}$ do.

13 Fakir Modak

14 Jai

$28750 \mathrm{M}$ do.

$28830 \mathrm{M}$ do.

15 Bodi

$28935 \mathrm{M}$

do.

$29025 \mathrm{~F}$

$29110 \mathrm{~F}$

do.

17 Chari

$29240 \mathrm{~F}$ do.

N1 Niece of No. 8

$\mathrm{C}_{3}$ His father had leprosy

18 Giri

19 Basi Mandalain 29335 F Mandal

N2 Nephew of No. 11

$\mathrm{N}_{1}$ Father of No. 12

$\mathrm{N}_{2}$ Brother of

$$
\text { No. } 13
$$
$\mathrm{N}_{1}$ do.

$\mathrm{N}_{2}$ Wife of No. 15

$\mathrm{N}_{1}$ Daughter of No. 16

$\mathrm{C}_{1}$ Wife of No. 11

$\mathrm{N}_{2}$ Relative of No.4 
Katras, in another part of the coalfield, Mr. G. G. Carapiet kindly lending an empty bungalow for the purpose. Meanwhile, the Dhanbad Municipality voted Rs. 1,500 for a clinic within the municipal area, which was opened in an out-house of the police station on 15th September. Owing to its unpopularity at that site, a small building was put up on the outskirts of the town and was occupied on 11th February, 1933.

Apart from the Rs. 1,600 allotted by the Jharia Mines Board of Health, and the Rs. 1,500 voted by the Municipality, the District Board has given Rs.500. Mr. G. G. Carapiet has interèsted himself whole-heartedly throughout in the collection of funds. He suggested that each labourer on the collieries should be asked to contribute from his pay four annas once a year. The idea was put to the various associations and to the collieries themselves, many of whom consented readily. Mr. Abel has applied the same scheme to the local railway workshops. The sum of Rs. 2,970 has been collected mostly from these sources and, considering the present industrial depression, the sum must be regarded as satisfactory.

The staff employed from the beginning has been :-

One Sub-Assistant Surgeon.

Two dressers trained at Purulia Leprosy Hospital.

One dresser trained locally.

One clerk and a handyman.

This "team" is comfortably housed at Jharia and travels by bus or train to Dhanbad and Katras to attend the clinics at those places. Sweepers are supplied from local sources as required.

At present clinics are held twice weekly at Jharia and Dhanbad, and once a week at Katras, though soon it will be necessary to hold two clinics a week at Katras. The following table shows the number of attendances at the various clinics during 1932.

Number of

Number of Attendances.

Clinics held. New cases. Old cases. Total.

\begin{tabular}{llrrrrr} 
Jharia & $\ldots$ & 82 & & 783 & 7234 & 8017 \\
Katras & $\ldots$ & 13 & & 84 & 642 & 726 \\
Dhanbad & $\ldots$ & 20 & & 96 & 1054 & 1150 \\
\cline { 5 - 7 } & & & & & & \\
\cline { 3 - 6 } & & Total & $\ldots$ & 963 & 8930 & 9893
\end{tabular}

It is obvious that any further extension of clinics means the employment of a second " team." When that becomes possible, an accurate survey of the collieries and villages 


\section{Leprosy Out-Patient Clinic, Dhanbad}

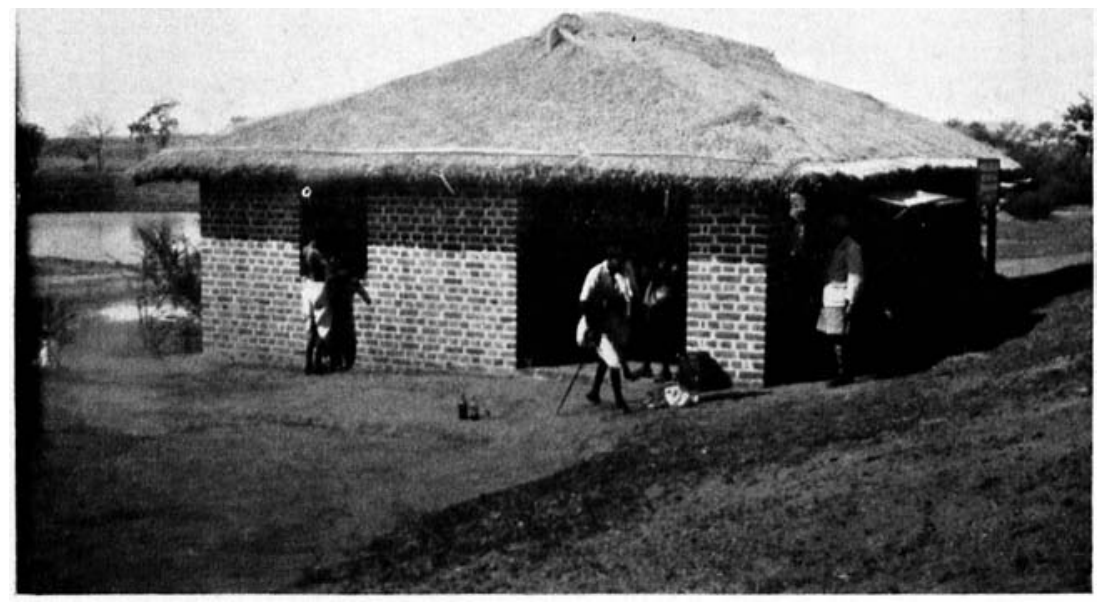

Viliw ol: BUH,ING.

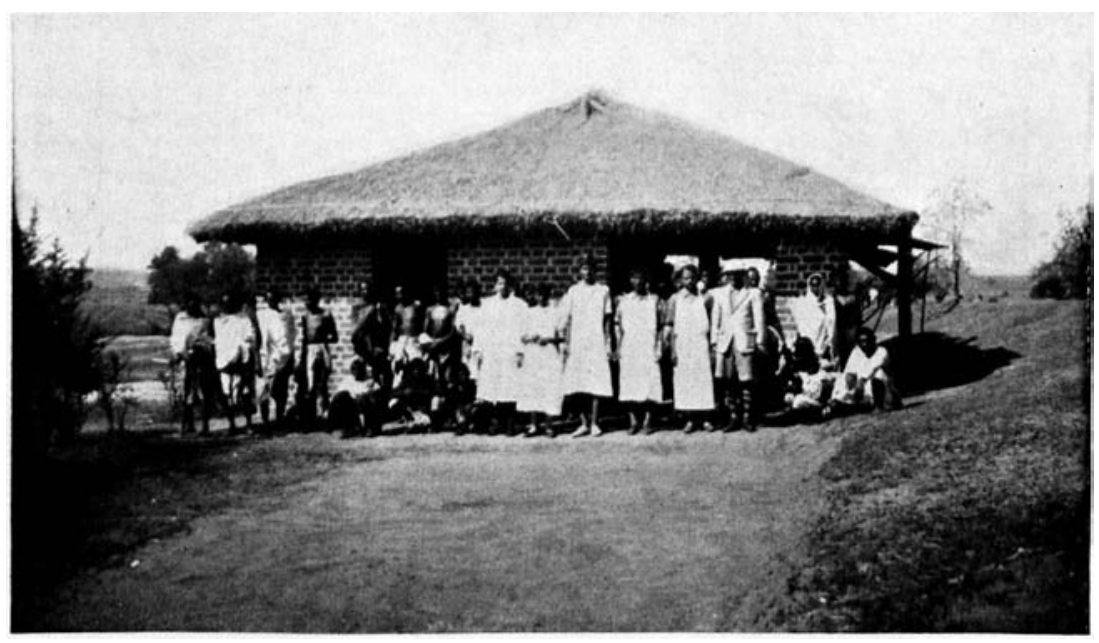




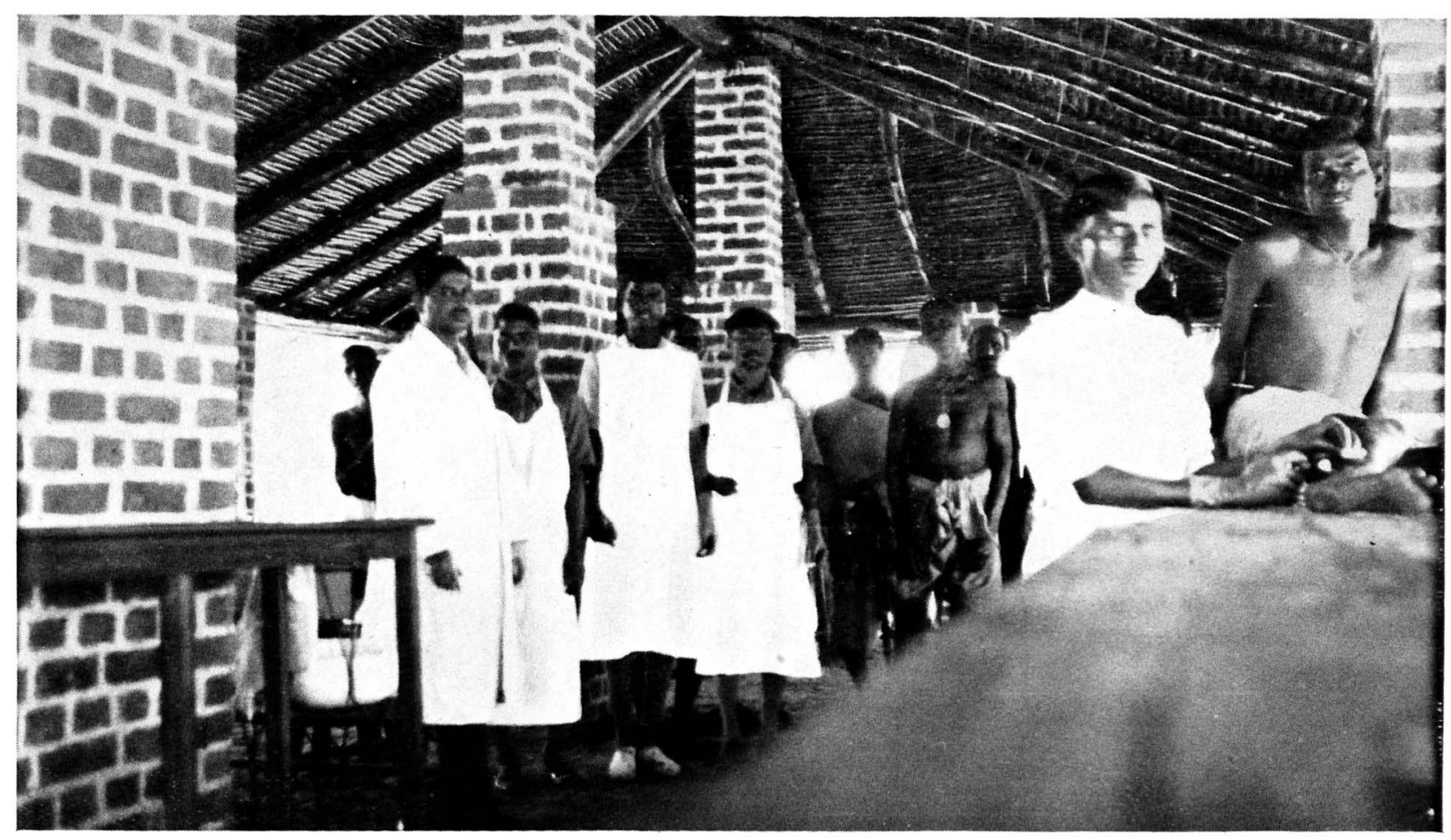

Inside of Leprosy Out-Patient Clinic, Dhanbad. 
must also be undertaken; for this purpose an extra doctor must be engaged who will also carry on propaganda work. At present, all Sanitary Inspectors are supplied with "village cards" (on Dr. Muir's lines) one for each village; upon each card a rough plan of the village is drawn and all cases discovered are entered on the plan as well as in the appropriate columns on the other side of the card. (See illustration facing page 123). The lantern operator already employed by the Board to go round the villages lecturing on general health subjects, is supplied with 36 slides on leprosy which are also shown.

On 10th January, 1933, the Jharia Mines Board of Health resolved to transfer its responsibilities in the question of leprosy to the Dhanbad and District Leprosy Relief Fund, subscribing Rs. 1,500 to the fund. The Board's Chief Medical Officer continues, nevertheless, to supervise and direct the work of the clinics; all correspondence and the checking of accounts and paybills is done in the Board's office; and in the Board's laboratory are prepared the Brilliant Green solution, the Hydnocarpus Oil and the Ethyl Esters used in treatment. Examination of clinical material and Kahn Tests are also carried out in the Board's laboratory.

The suggestion made in this paper that all Sanitary Inspectors should be trained to make preliminary surveys in the villages they visit, is an excellent one. These surveys will, naturally, not be so complete as one would wish, but if cards of the type illustrated were supplied to Sanitary Inspectors and health visitors, much might be learned of the prevalence and distribution of the disease, information which otherwise would be unobtainable.-EDitor. 